\title{
TITULIZACIÓN DE ACTIVOS Y SU TRANSFERENCIA A LOS PATRIMONIOS DE PROPÓSITO EXCLUSIVO
}

\author{
CPC. VÍCTOR E. VINCES YACILA \\ Mg. HERNÁN YACSAHUACHE PASAPERA
}

\section{INTRODUCCIÓN}

El Mercado de Valores como mecanismo de canalización directa de recursos, constituye una alternativa de financiamiento adicional a las actividades de intermediación financiera indirecta realizadas por los bancos.

En los últimos años, muchos bancos se valían de los subsidios cruzados para abaratar ficticiamente sus costos y reducir las comisiones a sus comitentes. Con esta forma de actuar, estaban eliminando paulatinamente a las Sociedades Agentes de Bolsa no bancarias y poco a poco arribarian a monopolio de la actividad bursátil.

La constitución de Sociedades Titulizadoras en el contexto del Mercado de Capitales en nuestro país, debido a la implementación de normas implantadas por la Comisión Nacional Supervisora de Empresas y Valores (permitiendo la promoción de productos financieros y físicos...) amplía la gama de productos y facilitan los mecanismos de negociación en la Bolsa de Valores.

A través de este mecanismo de financiamiento pueden participar directamente las unidades económicas como el sector público o gobiemo locales, propietarias de activos financieros y productos físicos (acciones, letras de cambios, certificados de moneda extranjera, terrenos, administradores de vías y cabo de peaje, etc.). Así por ejemplo, determinada empresa propietaria de miles de terrenos puede agenciarse de recursos frescos cediendo la construcción de un complejo hotelero, centros de recreación de verano o invierno y cederlo a su administración por varios años y vencido el plazo retorna dicho activo a la estructura patrimonial de la empresa o de la Municipalidad. Allí radica la tremenda importancia de esta vía de financiamiento empresarial.

\section{TITULIZACIONN DE ACTIVOS Y SU TRANSFERENCIAA LOS PATRIMONIOS DE PROPÓSITO EXCLUSIVO}

Definición.- En términos prácticos se reconoce a nivel internacional, como titulización de activos, a la transformación de activos líquidos o de lenta rotación en títulos valores que son colocados en los mercados de capitales.

De acuerdo a la Nueva Ley del Mercado de Valores, se define la titulización de activos como el proceso mediante el cual se constituye un patrimonio, que servirá para respaldar los derechos de los que adquieren los títulos valores.

La titulización de activos es una forma de obtener financiamiento o liquidez, y se logra a través de un proceso que comprende tres pasos: 
- La constitución del patrimonio

- La transferencia de los activos, y

- La emisión de los títulos valores respectivos.

De acuerdo a los conceptos teóricos, la titulización "es un proceso por el cual el originador o fideicomitente favorece a un tercero, de manera indirecta (fideicomisario o inversionista) al pagarle una tasa de interés, para lo cual transfiere sus activos a un fidenciario quien se encarga de la operación.

\section{Titulación de activos}

Es el proceso mediante el cual se constituye un patrimonio para respaldar el pago de derechos a titulares de valores emitidos con cargo a dicho patrimonio.

\section{Caracteristicas:}

a) El control del proceso de titulación de activos y la transferencia de los mismos está a cargo de CONASEV.

b) Activos que pueden ser titulizados: aquellos en los que el titular puede disponer libremente.

c) Sociedad Titulizadora: Sociedad Anónima de duración indefinida, cuyo objeto exclusivo es desempeñar la función de fiduciario en procesos de titulización.

d) Sociedad de Propósito Especial: Su patrimonio está conformado por activos crediticios y su actividad es la emisión y pago de valores mobiliarios respaldados con dicho patrimonio.

\section{NORMAS ESPECIALES RELATIVAS A PROCESOS DE TITULIZACIÓN}

Para efectos de las normas relativas a procesos de titulización contenidas en la presente ley, se entenderá por:
2.1 Activos.- Que pueden ser titulizados, aquellos en los que el titular puede disponer libremente.

2.2 Activos crediticios.- Los derechos incorporados o no en valores que confieren a su titular el derecho de percibir sumas de dinero.

2.3 Mejorador.- La persona que otorgue garantías adicionales para el pago de los derechos que confieren los valores emitidos en virtud de procesos de titulización.

2.4 Originador.- La persona en interés de la cual se conforma un patrimonio de propósito exclusivo y a quien se obliga a transferir los activos que lo integrarán.

2.5 Patrimonio de propósito exclusivo.Le permite respaldar al pago de los derechos incorporados en valores mobiliarios emitidos en un proceso de titulización.

2.6 Respaldo.- La garantía o fuente de recursos para el pago de los derechos que confieren los valores emitidos en procesos de titulización.

2.7 Servidor.- La persona que ejecuta el cobro de las prestaciones relativas a los activos integrantes de un patrimonio de propósito exclusivo..

\section{Normas aplicables y régimen de control.}

El Decreto Legislativo No 861 Ley de Mercado de Valores establece normas a las que deben sujetarse las personas que efectúen actos dentro de procesos de titulización:

a) En los casos en que un proceso de titulización se efectúe en forma parcial en el territorio nacional, las normas contenidas en el presente título 
(TÍTULO XI DEL DECRETO LEGISLATIVO No 861 LEY DE MERCADO DE VALORES. Normas Especiales Relativas a Procesos de Titulización) serán, salvo pacto contrario, de aplicación exclusiva a los actos que se efectúen en el país.

b) Comprende a CONASEV ejercer el control y la supervisión de las personas naturales y jurídicas que intervergan en los procesos de titulización.

c) Los patrimonios de propósito exclusivo; su titulización puede ser desarrollada a partir de los siguientes patrimonios de propósito exclusivo:

- Patrimonios fideicometidos, mediante fideicomisos de titulización.

- Patrimonios de sociedades de propósito especial y,

- Otros que resulten idóneos, según establezca CONASEV mediante disposiciones de carácter general.

3. ACTIVOS A TITULIZAR SU TRANSFERENCIA Y CONSTITUCIÓN DE PATRIMONIOS DE PROPÓSITO EXCLUSIVO

\subsection{Activos a titulizar y su transferencia} a los patrimonios de propósito exclusivo.- La Ley de Mercado de Valores $N^{\circ} 861$ en sus artículos $295^{\circ}$ al $300^{\circ}$ contemplan las apreciaciones técnicas pertinentes, a saber:

a) Activos que pueden ser titulizados.- La integración de patrimonios de propósito exclusivo pueden transferirse a todos aquellos activos y a la esperanza incierta a que hace referencia el Art. 1409 del Código Civil, sobre los que su titular pueda disponer libremente. CONASEV encuentra facultades para establecer, mediante disposiciones de carácter general, limitaciones a la utilización de determinadas categorías de activos.

b) Transferencia en activos.- La transferencia de activos a los patrimonios de propósito exclusivo se efectúa vía actos jurídicos, que corresponden de acuerdo a su naturaleza. Tratándose de cesión, ésta puede efectuarse en un acto único, individualizándose cada activo con indicación de sus características.

c) Transferencia por personas sujetas a supervisión y control especial.- Las unidades económicas sujetas a un régimen de control y supervisión especial de algún organismo público deberán sujetarse a las reglas que éste establezca para la enajenación de conjuntos de activos destinados a procesos de titulización.

d) Protección a los inversionistas.-No podrá declararse la nulidad, por simulación, la anulación ni la ineficiencia por fraude del acto, por el cual una o más personas naturales o.jurídicas constituyen un patrimonio de propósito exclusivo y se obligan a transferir activos para que se incorporen en dicho patrimonio, cuando pudiera derivarse en un perjuicio para quienes hubiesen suscrito $o$ adquirido los valores por oferta pública.

Las personas obligadas a transferir los activos no podrán, salvo pacto contrario, solicitar la rescisión por lesión, la resolución o reducción de su prestación por excesiva onerosidad de la misma, ni la resolución por incumplimiento del adquiriente del pago de la prestación debida en los supuestos allí señalados. 
e) Criterio para la determinación del perjuicio a los inversionistas.- Se ocasiona perjuicio a los suscriptores o adquirientes de los valores cuando deviene en imposible el pago de las prestaciones debidas a los titulares de los valores, se dificulta la posibilidad de efectuar dicho pago, o en todo caso, se provoque un descanso en la categoría de riesgo asignada.

f) Activos en poder del servidor.-El servidor debe mantener en forma separada los activos y los documentos relativos a estos activos que tenga en su poder en virtud del servicio prestado. En el supuesto que dicha persona ingresara en proceso de disolución y liquidación, las entidades que tengan a su cargo la liquidación deberán cuidar de entregar dichos activos y documentos al sustituto que se hubiera designado, de ser el caso, o a quien ejerza la titularidad del patrimonio de propósito exclusivo.

\subsection{Constitución de patrimonio de pro- pósito exclusivo.-}

\section{Fideicomiso de titulización}

En el fideicomiso de titulización, una persona denominada fideicomitente se obliga a efectuar la transferencia fiduciaria de un conjunto de activos a favor del fiduciario para la constitución de un patrimonio autónomo, denominado patrimonio fideicometido, sujeto al dominio fiduciario de este último y afecto a la finalidad específica de servir de respaldo a los derechos incorporados en valores, cuya suscripción o adquisición concede a su titular la calidad de fideicomisario.

Es importante destacar que únicamente las sociedades titulizadoras pueden ejercer las funciones propias del fiduciario en los fideicomisos de titulización.

\section{Sociedades titulizadoras}

Es la sociedad anónima de duración indefinida cuyo objeto exclusivo es desempeñar la función de fiduciario en proceso de titulización.

\section{Capital y patrimonio}

Su capital mínimo es de setecientos cincuenta mil nuevos soles $(\mathrm{S} / .750,000)$ y debe estar íntegramente suscrito y pagado antes de dar inicio a sus actividades.

Es importante mencionar que en ningún caso el Patrimonio Neto de las Sociedades Titulizadoras podrá ser inferior al monto del capital social mencionado anteriormente; el mismo que deberá ser incrementado en función al número y monto de los patrimonios sobre los que ejerza el dominio fiduciario, de acuerdo a las normas que para tal efecto dicte CONASEV.

\section{Factor, fiduciario y comisión administradora}

Por cada fideicomisario, la sociedad titulizadora designa una persona denominada factor fiduciario, quien asume personalmente su condición. Si fuera necesario el caso, la sociedad titulizadora designa una comisión administradora a cuyas decisiones se somete el factor fiduciario.

\section{Obligaciones especiales}

En virtud del fideicomiso, la sociedad titulizado/ra tiene, además de las señaladas en el acto constitutivo y en la Ley General, las siguientes obligaciones: 
a) Mantener los activos fideicometidos separados de los que integran su patrimonio y de los que corresponden a otros patrimonios fideicometidos.

b) Convocar a junta de fideicomisarios, cuando lo soliciten los que representen al menos la quinta parte de los derechos respaldados por el patrimonio fideicometido; o para solicitar instrucciones cuando así lo exijan las circunstancias.

c) Cumplir sus funciones de acuerdo con los términos establecidos en el acto constitutivo.

d) Elaborar estados financieros propios y de cada patrimonio bajo su administración.

\section{Supervisión y control}

El control y la supervisión se efectúan exclusivamente en relación a los patrimonios fideicometidos cuyos valores son objeto de oferta pública.

\section{Cesación del dominio fiduciario}

El dominio fiduciario de una sociedad titulizadora cesa por:

- Denuncia

- Ingresar en proceso de disolución y liquidación; y

- Disolución y liquidación: la disolución y liquidación de la sociedad titulizadora sólo afectará a su patrimonio propio y no a los patrimo-nios fideicometidos que se encontraban bajo su dominio.
BIBLIOGRAFÍA

BUENO CAMPOS, Eduardo

Dirección estratégica de la empresa, metodología, técnicas y casos. Editorial Pirámide S. A., Madrid.

CONASEV

Ley del mercado de valores. Decreto Legislativo $N^{\circ} 861$

CONASEV

Ley de fondos de inversión y sus sociedades administradoras. Decreto Legislativo $N^{\circ} 862$

CONASEV

Introducción a los mercados de futuros. En: Documento de investigación $\mathrm{N}^{\circ} 02$

SOBREMAZAO, Julio

Cómo invertir en bolsa. Editorial Paraninfo S.A., 1991.

CONASEV

Revista Técnica Valores, 1997. 